\title{
Atomism and Fundamentality
}

\section{Benjamin Schnieder ${ }^{1}$}

Received: 15 March 2020 / Accepted: 24 March 2020 / Published online: 19 April 2020

(c) The Author(s) 2020

\begin{abstract}
The paper focusses on two claims about metaphysical structure: Atomism and Fundamentalism. The first of these claims says that there are mereological atoms, i.e. minimal elements in the mereological structure of reality. The second says that there are fundamental truths, i.e. minimal elements in the grounding structure of reality. A philosopher who defended both of these claims was Bernard Bolzano; the present paper is an exploration of his views on the matter.
\end{abstract}

\section{Introduction}

\subsection{Two Metaphysical Claims about Structure}

Analytic philosophy has come a long way. Gone are the days in which you only counted as an analytic philosopher if you were a stout adherent to the tradition of the Vienna circle; also the days in which an avowal to ordinary language philosophy was considered the ticket to the club; and the days in which you had to be good a Quinean, a good Fregean, a good Kripkean, or what have you. Analytic philosophy has changed; it has become more inclusive and more tolerant to a wide range of topics, including some that its founding fathers abhorred. Even the big metaphysical questions have made their comeback, for better or worse.

Anyway, this paper contributes to a traditional metaphysical debate. It revolves around two claims about the structure of reality: Aтомism and Fundamentalism. Each of these claims is concerned with a particular relation that lends structure to reality, namely parthood and grounding, respectively.

The relation of parthood is a very mundane thing; the layman is as familiar with it as is the philosopher. The ordinary, medium-sized goods that surround us, and also we ourselves, are objects with parts: legs are parts of tables and of humans, feet are parts of human legs (and some table legs), cells are parts of human feet (and table feet if made of organic material), etc. It seems hardly necessary to say

Benjamin Schnieder

benjamin.schnieder@gmx.de

1 Fachbereich Philosophie, Universität Hamburg, Überseering 35, 22297 Hamburg, Germany 
much more about parthood by way of introduction. Now the claim about parthood to be investigated here is the thesis of Aтоміsм, which says that there are mereological atoms; very, very small things. Things that do not have any parts whatsoever. (Let me emphasize that Атоміsм is here defined as the purely mereological thesis that there are things without parts. Thus understood, Атоміsм must be distinguished from other historically prominent theses with the title 'atomism', such as Prescocratic atomism; see e.g. Curd 2019.)

While the relation of grounding is, arguably, also something that the layman already has some familiarity with, it seems in need of a few more introductory remarks. Not the least because the word 'grounding' is a term of the art, and because different philosophers may seem to use it in slightly different senses.

Grounding will here be understood as a productive, objective priority relation holding between truths (i.e. true propositions). ${ }^{1}$ Let me elaborate. First, productivity: the relation of grounding obtains between two truths if one of them owes its truth to the other; in that sense, the ground brings about the truth of its consequence. Consider, for instance, the true proposition that Socrates was a philosopher or a butcher; its truth is brought about by the truth that Socrates was a philosopher. Or consider the true proposition that the number of colors on Italy's flag is three; it owes its truth to the true proposition that the colors on the flag are green, white, and red. Second, grounding is an objective rather than an epistemic notion: the question is not how we come to know some truths, but rather how the truths themselves come about. Third, the relation of grounding is a priority relation: It is irreflexive (for: nothing is prior to itself), asymmetrical (for: if $x$ is prior to $y$ then $y$ is not prior to $x$ but rather posterior to it), and transitive (for: if $x$ is prior to $y$, and $y$ is prior to $z$, then $x$ is prior to $z$ as well). Due to these properties, grounding induces a partial order on the totality of truths.

Grounding can be indicated with different linguistic devices, including the predicate ' $x$ grounds $y$ ', the sentential connective ' $p$ because $q$ ', and the philosopher's favorite: ' $p$ in virtue of $x$ '. Finally, the relation of grounding has explanatory value: knowledge of the grounds of a truth helps us understand why it is a truth, and thus contributes to its explanation.

Once the notion of grounding is understood, a question naturally arises: Are there fundamental elements in the order of grounding? That is, are there fundamental truths, propositions that are true but do not owe their truth to any other, more fundamental truths? The affirmative answer to this question is the thesis of FundAMENTALISM.

Atomism and Fundamentalism are claims of the same form: In abstract terms, each of them asserts that there are minimal elements in a structure induced by a certain relation - in one case the relation of parthood, in the other that of grounding.

\footnotetext{
${ }^{1}$ For conceptions of grounding along these lines, see e.g. Rosen (2010), Fine (2012). In the contemporary debate, grounding is often, but not always, regarded as relating facts rather than truths (Rosen 2010, e.g., focusses on facts, while Fine 2012 switches between facts and truths). A reason to prefer truths here is that it is Bernard Bolzano's preference, and his conception of grounding will be a central concern of the paper.
} 
This parallel between the claims does not by itself mean that if you endorse one, you must endorse the other. But, as we will later see in more detail, they go together pretty well.

Finally note that many philosophers who endorse ATOMISM and Fundamentalism not only regard them as true, but as necessarily true. This view certainly comes natural for someone who embraces the claims on the basis of some a priori arguments (like those I will consider in this paper).

\subsection{Analytic Philosophy and the History of Philosophy}

Having introduced the two claims that form the topic of this paper, I should now add something about how I will approach them, and why I chose the approach I did.

The relation of grounding stands in the limelight of contemporary metaphysical debates; it is a hot topic in metaphysics. That it emerged to be a hot topic is a comparatively recent development. But the topic itself is not a new discovery in philosophy. To the contrary, it is as old as philosophy itself, even if parts of the ongoing debate may camouflage this fact. What is of recent origin is only its re-discovery, the renewed interest in it. Unfortunately, though, some papers in contemporary metaphysics may indeed read a bit like reinventions of the wheel. This is fodder for certain critics of analytic philosophy in whose eyes analytic philosophers tend to be intellectual isolationists and oblivious not only to other philosophical traditions but even to the history of their own philosophical debates. And while I think such criticism is often exaggerated, it is not completely wrong either; traditionally, the relationship status of analytic philosophy and the history of philosophy used to be: it's complicated. Thus, it happened only very recently that the journal Analysis (a founding journal of analytic philosophy) changed its editorial policy and started to welcome submissions on the history of philosophy. Or, to cite but one other example for illustration: GAP.10 - the 10th conference of the GAP (the German Society for Analytic Philosophy), at which this paper was delivered as the Erkenntnis lecturewas only the second instalment of the GAP conferences with an own section on the history of philosophy. Because of this, and because the motto of GAP.10 was pluralism in philosophy, I came to think that a suitable topic for the Erkenntnis lecture may well be a more historical take on metaphysics. I would hope I can thereby contribute to a pluralism of methods and approaches in analytic philosophy and demonstrate that our ancestors had insightful things to say about the issues we are still debating these days.

I chose for this purpose a philosopher who 200 years ago discussed the topic of grounding in impressive detail, anticipating many elements of the contemporary debate: Bernard Bolzano. ${ }^{2}$ Because of the depth and modernity of his work on

\footnotetext{
${ }^{2}$ For Bolzano's mature theory of grounding ('Abfolge'), see WL II, $\$ \$ 198-222$. His views need no further introduction here because my initial presentation of the idea of grounding in Sect. 1.1. was designed to match Bolzano's views. Note only that Bolzano's basic notion is that of immediate grounding, which is why he considers grounding to be intransitive (WL II, §213). This paper, however, works with the transitive relation of mediate grounding. Bolzano acknowledges such a relation as well, defined as the transitive closure of immediate grounding ( $W L$ II, §218). For surveys of Bolzano's conception of grounding in line with how I understand his views, see Tatzel (2002), Rumberg (2013, pp. 429-442), Roski and
} 
grounding, Bolzano recently found his way into Kit Fine's Essential Glossary of Ground, in which Bolzano is given the honorific title of the groundfather.

In his discussions, Bolzano raised the question whether there are fundamental truths, i.e. fundamental elements in the order of grounding. And he emphatically endorsed the affirmative answer; he firmly believed in Fundamentalism. Moreover, Bolzano was also interested in mereology and he had an equally firm belief in the thesis of Атоміsм. In what follows, I want to examine two arguments he gave for the two claims. The argument for Fundamentalism is short and I will deal with it quickly (see Sect. 2). The main focus will lie on the argument for АтоміSм (see Sect. 3), which is complex and not particularly easy to assess. Interestingly, although the notion of grounding does not feature in the thesis of Aтоміsм, we will see that Bolzano's argument for the thesis is based on considerations about grounding.

\section{Quick Routes to Fundamentalism?}

In his early treatise Contributions to a Better-Grounded Presentation of Mathematics (published in 1810), Bolzano gave what he called a 'short proof' of FUNDAMENTALISM:

[T]o claim that all judgements are provable means to accept a series of consequences in which no first ground appears, i.e. no ground such that it is not in turn a consequence. But this is absurd. On the contrary, therefore, one must necessarily accept some judgements [...] which are themselves not consequences but fundamental judgements. (Bolzano, Beyträge II, §13)

Two notes on Bolzano's terminology are in order: First, when he says 'judgements' here, he does not mean mental episodes — acts of judging-but rather possible contents of such episodes, i.e. propositions or Fregean thoughts. ${ }^{3}$ In his mature philosophy, Bolzano will call these abstract entities propositions in themselves ('Sätze an sich'). ${ }^{4}$ Second, when Bolzano talks about provability here, he has in mind explanatory proofs which show why something is the case and not merely that something is the case. And he thinks that explanatory proofs establish a conclusion on the basis of its grounds. So he freely switches between talk of provability and talk of being grounded here.

Footnote 2 (continued)

Schnieder (2019, §2). For an in-depth discussion of Bolzano's conception, see Roski (2017). See also Casari (2016: ch. 7) and Morscher (2016) for further reconstructions of Bolzano's theory (but note that they are developed in conceptual frameworks which differ from the one presupposed in this paper).

3 The claim that propositions are possible contents of judgements is an informal means to get a grip on Bolzano's notion of a proposition. But strictly speaking, there are exceptions to the claim if some propositions are so evidently false that they could never be judged true (compare WL I, §42: 175f.) In any case, however, Bolzano does not think that the concept PROPOSITION can be analyzed as POSSIBLE CONTENT OF A JUDGEMENT; he is not certain whether the concept is analyzable at all (WL I, §23).

4 For Bolzano's mature conception of propositions, see WL I, §§19-22, and compare Künne (1997). 
Now what should we make of Bolzano's short proof of FundamentaLism? I think it is fair to say that, at best, his argument is not particularly transparent; at worst, it seems little more than a petitio principii. The first step of the argument is clear and correct: By a sequence of consequences (or: of grounds, which I henceforth say), Bolzano means a sequence that contains a consequence and all of its immediate or mediate grounds. Now if there are no fundamental truths then every truth is grounded; so there are sequences of grounds which do not contain any first ground or fundamental truth (simply because there aren't any first grounds). The second step is the problem: Exactly why should it be absurd that there are such sequences? The real burden of the argument is to give a reason for this assertion; but we are given none.

There is a traditional reason against unfounded sequences of grounds worth mentioning, if only for the fact that Bolzano explicitly rejects this reason. It consists in the realization that such sequences must have infinitely many elements (due to the irreflexivity and transitivity of grounding) paired with the belief that infinite grounding chains are impossible. However, Bolzano does not follow suit. He thinks infinite chains of grounds are not only possible but abound in reality. ${ }^{5}$ To see why, we first need to know something about Bolzano's conception of causality. ${ }^{6}$ He sharply distinguishes causation as a relation holding between concrete entities, as for instance events, from grounding, a relation holding between abstract entities, namely true propositions. But he believes that whenever an event $x$ causes an event $y$, the truth that $x$ occurs grounds the truth that $y$ occurs. Due to this link every cause is correlated to a ground; any infinite causal chain would therefore correspond to an infinite grounding chain. And Bolzano thinks it is easy to find infinite causal chains, even in small time intervals. He considers the movement of a material object from one position to another; let us call its initial position $I$ and its terminal position $T$. Now take any position in the trajectory of the object; let us call it $p_{l}$. The object's passing through $p_{1}$ is a cause of the object's finally reaching $T$. Now take another point, $p_{2}$, that lies between $I$ and $p_{1}$. The object's passing through $p_{2}$ is a cause of the object's passing through $p_{1}$. Since space is not discrete we can repeat this procedure ad infinitum: there is another point, $p_{3}$, lying between $I$ and $p_{2}$, and passing though this point is a cause of passing through $p_{2}$, etc. The following figure illustrates the scenario:

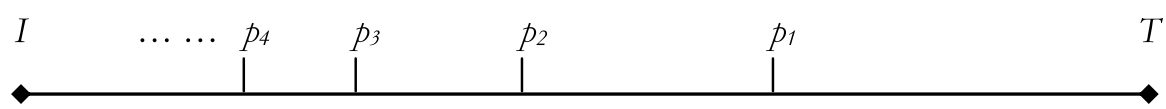

\footnotetext{
${ }^{5}$ While the following reasoning is from $R W$ I, $§ 68$ (see Roski and Schnieder 2019, $§ 3$ for discussion), Bolzano already stressed in Beyträge $§ 13$ that his belief in first grounds is not based on considerations about infinity.

${ }^{6}$ For the following, see WL II, §201. On Bolzano's conception of causation, see Schnieder Schnieder (2014).
} 
Hence, we can construct an infinite chain of causes; and for Bolzano such a chain corresponds to an infinite chain of grounds. ${ }^{7}$ So Bolzano embraces infinite grounding chains, but he also thinks that for any such chain there must be a fundamental (i.e. ungrounded) ground. Unfortunately, this only shows how not to understand his terse argument from the Beyträge (considerations about infinity are irrelevant); it does nothing to support the argument nor to help explain what idea is driving it.

Incidentally, some decades after writing the Beyträge, Bolzano himself had become dissatisfied with his argument. When he addressed the issue of fundamental truths in his opus magnum, his Theory of Science (published in 1837), he reiterated his belief in fundamental truths; but, with the intellectual honesty that was characteristic of him, he added the admission that he is unable to produce 'a proof of this that is satisfactory even to myself.' ( $W L \$ 214: 374)$ So he did not consider his 'short proof' from the Beyträge as a genuine proof any more.

Still, Bolzano is not the only philosopher who ever thought that an argument for the fundamental can be that quick. Jonathan Schaffer, for instance, may seem to be in the same boat. He also argues for FUNDAMENTALISM, although he understands the thesis slightly differently: For him grounds can be entities of any sort, since by 'grounding' he means a sort of ontological dependence. ${ }^{8}$ A fundamental entity then is one which exists, while its existence is not grounded in anything.

Now Schaffer appears to give a brief argument for FundAMENTALISM that is even more compact than Bolzano's:

There must be a ground of being. If one thing exists only in virtue of another, then there must be something from which the reality of the derivative entities ultimately derives. (Schaffer 2010, p. 39)

Whoever scolds Bolzano for the scarceness of his argument for the fundamental will presumably not find much praise for Schaffer's argument either.

As it happens, in personal communication Schaffer confirmed that the quoted passage is meant to mobilize an argument. He also said that, like Bolzano, he does not think the argument builds on the view that infinite chains of grounds would be problematic; instead, the argument is essentially concerned with an idea of inheritance: Consequences inherit their being from their grounds; but if grounds themselves always inherit their being from further grounds, nothing can ever come to possess being in the first place.

\footnotetext{
7 Bolzano gives a second example of an infinite causal chain, based on the assumption that time stretches out infinitely into the past (WL II, §216, p. 377; compare Roski and Schnieder 2019, §3). Nowadays, Bolzano's causally based infinite grounding chains would presumably not fall on many open ears because most metaphysicians would reject the strong causality-grounding link Bolzano endorses (for a dissident voice, see Wilson 2018). But in a similar fashion one can also construct non-causal infinitary grounding chains; see Dixon (2016, §4) and Roski and Schnieder (2019, §3).

8 Thus he talks about 'grounding (ontological dependence, priority in nature)' (Schaffer 2009). But note that Schaffer wants to subsume what I have called grounding under his notion as well; he would here see a case of ontological dependence between facts. This view is criticized in Schnieder (2017) and Ryhdéhn (2018).
} 
I may certainly have misunderstood what Schaffer told me, and/or misremember it. But if not, then I would like to point out that in my view, employing the idea of inheritance does not make the quoted argument any stronger. This is why: Talk about inheritance is, of course, somewhat metaphorical here. In the primary sense of word, people inherit possessions from other people. Now is there anything about this notion that forbids unfounded chains of inheritance? The past might extend into infinity; and in a universe in which it does, there may also have been people from eternity on. And finally it seems to be at least an epistemic possibility that there is some object, say: a rock, which at every time was in the possession of someone who once inherited it from someone else, and so on and so forth. We certainly do not conclude that nobody possesses a rock in this universe. Infinite chains of inheritance that do not bottom out in non-inherited possession are not per se unthinkable. So I fail to see how the notion of inheritance might help out Schaffer's little argument.

$\mathrm{Be}$ this as it may, I for one doubt there is any short route to FUNDAMENTALISM. There certainly are other, more complex arguments for this claim which may be more promising. Bolzano himself develops one, namely the ARGUMENT FROM REDUCTION: Its core idea is that grounding goes along with a reduction of complexity: complex truths are grounded in simpler truths; but complexity cannot be reduced ad infinitum, so grounding chains must terminate. ${ }^{9}$ Spelling this argument out requires a number of substantial assumptions, though, which is why Bolzano was not perfectly confident of it. ${ }^{10}$ Anyway, I want to move on to Bolzano's argument for АтомISM now. Afterwards I will briefly return to the issue of FUNDAMENTALISM, since the main idea of Bolzano's argument for AтомISM seems to be applicable to FUNDAMENTALISM as well.

\section{Aтомıмм}

\subsection{A Thesis in Need of an Argument}

Атоміsм is the thesis that there are mereological atoms, entities which have absolutely no parts. If Атоміsм is false, then everything must be infinitely complex; every entity must have parts, and its parts must have parts themselves, etc. A world in which Атоміsм fails would be made of what philosophers nowadays call gunk. Most philosophers agree that the idea of gunk is at least not evidently incoherent; it is epistemically possible that the world is gunky. So whoever endorses Aтомism is in need of an argument.

\footnotetext{
9 WL II, $\$ 221.3$.

10 On the Argument From Reduction, see Roski and Schnieder (2019: §5).
} 


\subsection{Bolzano's Argument for Aтоміsm}

Bolzano works out such an argument. But before I turn to it, let me provide some context: Bolzano presents his argument amidst his discussion of propositions and their non-propositional components, which he calls ideas in themselves (henceforth, I will simply speak of ideas). ${ }^{11}$ Just as propositions, ideas are not mental episodes but rather abstract entities which are potential contents of mental episodes. More precisely, ideas are potential contents of acts of thinking of something as something, such as the act of thinking of Frege as the inventor of modern logic; in such an act, we grasp an idea. (Note that you may sometimes think of something that does not really exist; in Bolzano's view, you still grasp an idea then, but one with an empty extension.)

Importantly for our present concerns, Bolzano endorses a conception of mereologically structured ideas and propositions. For him, ideas are literally parts of propositions, and sometimes propositions are parts of other propositions; thus, the proposition that cows ruminate is part of the proposition that cows ruminate or waves oscillate. Moreover, ideas can be parts of other, more complex ideas; for instance, the idea NUMBER is part of the idea IRRATIONAL NUMBER. Bolzano moreover held that the identity of an idea does not only depend on what parts it has but also on how those parts are arranged. Thus, on a final level of analysis, the ideas LEARNED FATHER OF AN UNLEARNED SON and UNLEARNED FATHER OF A LEARNED SON are composed of the same components; but since these components are arranged in a different order, we get two different ideas (after all, their extensions do not overlap). ${ }^{12}$

In accordance with this mereological conception of ideas, Bolzano conceived of conceptual analysis as the determination of the parts of a given idea, and the way those parts are combined so as to form the idea analyzed. ${ }^{13}$ Insofar an idea has components that are themselves complex ideas, one can distinguish between analyses of different depth; an ultimate analysis would decompose an idea into components that allow for no further analysis. Such components would be simple ideas, where

[b]y a simple idea, as the word indicates, I mean an idea which has no parts whatever, neither mere ideas nor complete propositions. (WL I, §61, p. 263)

Are there such ideas? Bolzano has made up his mind; he writes:

I believe that I can show in the following that there are such simple ideas. (loc. cit)

What follows is an argument for the existence of simple ideas. Since simple ideas are mereological atoms, Bolzano's argument, if successful, also establishes Aтоміsм.

Having clarified the context of Bolzano's argument, it is high time to turn to its substance:

\footnotetext{
${ }^{11}$ For Bolzano's views on ideas see WL I, §§48-78, and compare Künne (2001).

12 See $W L \mathrm{I}, \S 56$.

${ }^{13}$ See $W L$ III, $\$ 350$.
} 
Every object, even the most complex, must have parts that are not themselves complex, but altogether simple. [...] Therefore, any idea, however complex it may be, even if it contains infinitely many parts (if that is possible), must have parts that do not allow further division. These simple parts cannot be propositions, since every proposition, taken as such, is complex. Since the only parts of ideas are either propositions or other ideas, the simple parts must be ideas. (WL I, §61, pp. 263f.)

This is a pretty straightforward argument. One can paraphrase it as follows:

$\mathbf{P}_{1}$ There are ideas.

$\mathbf{P}_{2}$ Every object is either complex or simple.

$\mathbf{P}_{\mathbf{3}}$ Every complex object has simple parts.

$\mathbf{P}_{4}$ Every part of an idea or a proposition is either an idea or a proposition.

$\mathbf{P}_{5}$ No proposition is simple.

C Hence, there are simple ideas.

This argument is neat and it is valid. Whether it is sound or not depends on the truth of its third premise-the other premises seem unproblematic.

The third premise, however, is very substantial. It directly presupposes Атоміsм, but it is even a stronger claim: Since the thesis I called Атоміsм only says that there are atoms, it is compatible with the possibility that some objects are composed of mereological atoms while others consist of gunk. The third premise in Bolzano's argument, however, excludes such a scenario as it says that every composite object contains atoms (he indeed thinks that every object is, on a final level analysis, exclusively composed by atoms).

So, the crucial, third premise of Bolzano's argument is clearly itself in need of an argument. And Bolzano provides one. It fills the ellipsis indicated in the passage quoted above. Note that in principle one could isolate the argument and discuss it on its own, without considering the argument for simple ideas in which it appears. It is instructive, however, to know the larger context since it shows how in Bolzano's view Атоміsм is of relevance to philosophical areas apart from pure metaphysics. Incidentally, Атоміsм also plays an important role for Bolzano's philosophy of mind since he argues that a thinking subject must be a simple, i.e. atomic, substance. ${ }^{14}$

Now let us turn to Bolzano's argument for the claim that every composite object contains simple parts (i.e. $\mathbf{P}_{\mathbf{3}}$ ). For his argument, he distinguishes two cases: objects that have only finitely many parts, and objects that have infinitely many. The first case is simple.

If the number of parts of which a whole consists is finite, then the truth of this claim [i.e. that the whole contains simple parts] is evident. For, in this case we must come to indivisible, i.e., simple, parts after a finite number of divisions, e.g., bisections. (WL I, §61, p. 264)

\footnotetext{
${ }^{14}$ See $A T$, pp. 21-47, and compare Simons (2015) on how Bolzano's simple substances are inspired by Leibniz's monads.
} 
Bolzano makes a simple combinatorial point:

- Assume, a given object $a$ has $n$ parts.

- Now pick any one of them; let's call it $b_{1}$.

- Either $b_{1}$ is atomic or it has parts.

- If the latter, pick one of them, $b_{2}$. Either $b_{2}$ is atomic, or it has a part $b_{3}$.

- After at most $n-1$ such steps, we find an atomic part of $a$.

There is only one implicit presupposition involved here, namely that parthood is transitive: Parts of parts are parts of the whole. This indeed seems an unproblematic assumption. Even though, the assumption is not unproblematic for Bolzano, since he himself argues against the transitivity of parthood, based on alleged counterexamples: ${ }^{15}$ The $d u o$ Laurel and Hardy consists of exactly two parts. But Laurel and Hardy have body parts, for instance five fingers and five toes each; that does not entail, however, that the duo after all consists of twenty parts and more, instead of exactly two.

Whatever one makes of such cases, Bolzano's opposition to the transitivity of parthood is in tension with his argument for Aтоміsм which presupposes the transitivity of parthood. Perhaps the tension can be relieved by resorting to a distinction Bolzano makes between two kinds of complexes, those for which transitivity of parthood holds and those for which it does not. ${ }^{16}$ But I will not pursue this further and simply grant the transitivity of parthood for the sake of the argument.

So let me move on to the second half of Bolzano's case distinction.

However, there may be wholes which contain an infinite number of parts, as we find, for example, in any spatial extension, any line, surface or solid. (loc. cit.)

Bolzano believes that every line is composed of infinitely many points, which are its parts. But this view is not what he presupposes at this juncture, because points are simple objects and he is in the process of establishing the existence of simple objects in the first place. He rather makes the less contentious assumption here that every line contains infinitely many lines as parts; you can divide every line into two, and the lines obtained again, and again. He continues:

In the case of such objects, no division, if it generates only a finite number of parts, like a bisection or trisection, etc., will yield simple parts, no matter how often we repeat it. This creates the illusion that such an object does not even consist of simple parts. I claim, nevertheless, that such a whole, too, must have parts which are simple. (loc. cit.)

What now commences is the crucial, and most challenging part of the argument. It consists of three steps. First:

${ }^{15} W L \mathrm{I}, \S 83$.

16 WL I, $\S 84$. 
[i] Compositeness is an attribute which obviously cannot exist without there being parts that produce it (i.e., parts that contain the ground or condition for it). (loc. cit.; my numbering)

Let me pause and elaborate. First, a terminological remark: Bolzano uses the term 'condition' for grounds of a particular kind, namely grounds that are required for what is grounded. ${ }^{17}$ What essentially carries the weight of the argument, however, is the pure notion of a ground; so one can henceforth simply read 'condition' as 'ground'.

Second, as to the content of the passage, Bolzano starts his argument with the contention that compositeness (or: complexity) is not a fundamental property. Given a composite object, you can always ask what makes it a composite one? And the question can be answered with recourse to its parts: The object is composite because those other objects are its parts and compose it. (Bolzano puts this somewhat metaphorically in saying that the parts contain the said ground; what is meant is that the ground is concerned with them.)

Essentially, Bolzano here repeats a point that Plato already made in his Euthyphro dialogue: ${ }^{18}$ If something is a carried thing, it is so because this or that object carries it. If someone is a loved one, s/he is so because this or that person loves her/him. And if something is a composite or composed thing, it is so because these or those objects compose it. Behind these examples stands a general idea: Some monadic predicates (such as ' $x$ is a composite object') correspond to relational properties, where to possess such a property is to stand in a relation to some object or objects. Some monadic predicates wear their relational character on their sleeves since they are derived from two-place predicates (e.g. ' $y$ is beloved', being derived from ' $x$ loves $y$ '); others do not (e.g. ' $x$ is famous'). Now if a given object $x$ stands to another object $y$ in a relation $R$, then because of that $x$ has the relational property of standing in $R$ to $y$, and also the less specific relational property of standing in $R$ to some object. So any monadic predicate which corresponds to this relational property applies to $x$ for the same reason, namely because $x$ stands in $R$ to $y .{ }^{19}$

\footnotetext{
17 WL II, §168.4.
}

${ }^{18}$ Euthyphro, Stephanus page 10b. The above take on Plato's point is defended in Schnieder (2015, pp. 243-46).

${ }^{19}$ With the aid of contemporary logical tools and the theory of grounding, one can embed Bolzano's and Plato's intuition into a more rigorous framework. One can deal with relational properties by lambda abstraction: Given a predication with a two-place predicate ' $R a b$ ' (meaning, for instance: $a$ loves $b$ ), we can construct a predication with a corresponding one-place predicate: $\lambda x(R x b)(a)$ (which would roughly mean: $a$ has the property of loving $b$ ). The predications are connected by a grounding link (Fine 2012, pp. 67-71) which we can indicate by using ' $<$ ' as a symbol for (full or partial) ground: $R a b<\lambda x(R x b)(a)$. In words: that $a$ and $b$ stand in relation $R$ grounds that $a$ has the property of standing in $R$ to $b$.

Now assume Ann loves Ben: Rab. It follows that someone loves Ben: $\exists x R x a$. In turn, it follows that Ben is a loved one: $\lambda x \exists y(R y x)(a)$. We get three corresponding grounding links. First: Rab $<\exists x R x a$. (This holds because existential quantifications are grounded in their true instances; see, e.g., Rosen 2010, p. 117; Fine 2012, Section 1.7.). Second: $\exists x R x a<\lambda x \exists y(R y x)(a)$. By the transitivity of grounding, we obtain: $R a b<\lambda x \exists y(R y x)(a)$. That a given man (Ben) is a loved one is therefore grounded in the fact that another given person (Ann) loves him.

The case for composition is structurally analogous but involves a slight complication since objects are composed of variable numbers of entities. One can capture this by resorting to plural quantification. Let 
Bolzano's argument therefore has a strong start: The compositeness of an object is not a fundamental property; its possession is grounded in the fact that some things compose the object and thus become its parts. Now for the second and third step of Bolzano's argument.

[ii] If these parts are themselves composite, then they merely explain a compositeness of a certain kind (namely of such and such parts), but not the compositeness that happens at the whole in general.

[iii] So in order to explain the latter, and to explain it sufficiently, i.e. [by] a condition of it that does not require any further condition, there must be parts that are no longer complex, but simple. (loc. cit.)

All of this reads mildly obscure. Let me start with some comments highlighting central, problematic elements. First: Bolzano has a sophisticated theory of grounding and he sometimes says that grounds explain what they ground. This is how we should understand talk about 'explanation' here: an explanation of a phenomenon specifies its grounds and thereby explains it.

Second: Now Bolzano not only speaks of an explanation here, but of a sufficient explanation. This, however, is not a technical term he introduces or uses anywhere else. Whatever sense we make of this notion must basically come from this very passage, and it does not seem trivial to interpret it.

What Bolzano says is that a sufficient explanation must invoke a condition which requires no further condition. ${ }^{20}$ But although he says this, he cannot really mean it. For, the idea of the argument is that the simple parts of a complex object provide the sufficient explanation of its compositeness. But the simple parts of an object are not, in general, objects which lack further conditions; nor would Bolzano say they are. He considers bodies to be collections of atomic substances. But he does not regard such atomic substances as unconditioned entities, since he thinks that they are conditioned by their creator, i.e. God. In fact, Bolzano thinks every contingent object has God as a condition, and he thinks that God is the only unconditioned concrete entity (and although it might be clear enough, let me emphasize that Bolzano does not regard God as a part of ordinary contingent objects). ${ }^{21}$ So, when Bolzano holds that a sufficient explanation of the compositeness of an object must proceed

(i) in terms of its parts, and also

\footnotetext{
Footnote 19 (continued)

us use capital letters for plural variables ' $X$ '. Now assume Ben (this time not a person but a damaged statue of a person) is composed of head and trunk: Rabc. It follows that some entities compose Ben: $\exists X R X c$. In turn, it follows that Ben is a composed object: $\lambda x \exists X(R X x)(a)$. We get three corresponding grounding links. First: Rabc $<\exists X R X a$. Second: $\exists X R X a<\lambda x \exists X(R X x)(a)$. Third: $R a b c<\lambda x \exists X(R X x)(a)$. That a given object (Ben) is a composed one is grounded in the fact that some given objects (Ben's head and Ben's trunk) compose it.

${ }^{20}$ Bolzano may have taken on terminological loan from Leibniz, who famously speaks of sufficient reasons and says that a sufficient reason 'needs no further reason' (Principles, §8). Notice, however, that in German Leibniz's sufficient reasons are standardly called 'zureichend', whereas Bolzano uses the synonymous term 'genügend'.

${ }^{21}$ See $R W$ I, $\$ 66$.
} 
(ii) in terms of a condition which requires no further condition,

he must be taken with a solid grain of salt. The question is: how so, exactly?

Third: In passage [ii], Bolzano sounds particularly obscure; he talks about the compositeness that happens ('Statt findet') at a whole, which sounds like a category mistake. Properties are possessed by objects and objects have them; but unlike events, properties do not happen, and Bolzano does not speak that way elsewhere. Moreover, what should we make of the contrast between the compositeness of a certain kind and the compositeness taking place at the whole in general?

If nothing else is clear here, then at least this: The quoted passage is surprisingly opaque for Bolzano's otherwise lucid style of writing. ${ }^{22}$

\subsection{A Predecessor of Bolzano's Argument}

Perhaps, a footnote to Bolzano's passage hints at a partial explanation of its opacity. In his Theory of Science, Bolzano quite often references Hegel, and almost always in order to criticize him, in particular for his obscurity. In the footnote to this passage, Bolzano also references Hegel-but approvingly. 'Hegel viewed the matter in the same way,' he writes. Which makes one wonder: Could Hegel actually help us here to get clearer about what Bolzano means ? $^{23}$

Let us give it a try. Bolzano directs us to the following passage from Hegel's Science of Logic:

That the composite is not one thing in and for itself but is something only externally put together, that it consists of something other, is its immediate determination. But this something other than the composite is the simple. It is therefore a tautology to say that the composite is made up of the simple. (Hegel, Science, section II, ch. 1, remark 2)

Thus far, we do not get much help for understanding Bolzano; nor do we get a good argument. The only uncontroversial sense in which a composite thing must be composed of something other is that it must be composed of things non-identical to it, since parthood is irreflexive:

Consist If $x$ consists of (i.e. has as parts) $y$ and $z$, then $x \neq y$ and $x \neq z$.

\footnotetext{
22 To make things worse, the German version of [iii] contains a slip of the pen that has to be corrected for the passage to make any sense at all. It reads: 'Um also diese [...] genügend zu erk-lären, d.h. als eine Bedingung zu ihr, die keiner weiteren Bedingung bedarf ...' (my emphasis). Literally this means: 'In order to explain this [i.e. the compositeness] sufficiently, i.e. as a condition of it which does not require any further condition .... However, we do not want to explain the compositeness as a condition but rather by one of its conditions. The German must actually read: 'Um also diese [...] genügend zu erklären, d.h. durch eine Bedingung zu ihr, die ...'.

23 Two further sources that may have inspired Bolzano are (i) Leibniz's Monadology, §2, and (ii) Wolff, Vernünffige Gedancken, §76. Wolff's argument explicitly relies on an idea about grounding. A crucial difference to Bolzano's argument is that Wolff's argument relies on the Principle of Sufficient Reason; Bolzano rejects this principle (AT 179f.; WL II, §214).
} 
But in order to conclude that a composite thing consists of simples, Hegel needs something much stronger, namely that a whole must be composed of things of a different kind than the whole:

Consist* If $x$ consists of (i.e. has as parts) $y$ and $z$, then $y$ and $z$ are not of the same kind as $x$.

This, however, is certainly no tautology, contrary to what Hegel suggests. As it stands, one can all too easily argue against the principle. Imagine a wall consisting of one hundred bricks. While the kinds wall and brick are different, there are nevertheless (non-trivial) kinds to which both the wall and the bricks belong, such as the kinds substance, material object, or also artefact. Moreover, every material object consists of other material objects; matter always consists of further matter. So unless one specifies a restricted understanding of 'kind', principle Consist* seems rather hopeless.

Hegel himself does not really seem to think his remark already settles the issue; for, he continues with his argument:

To ask what something consists of is to require the production of something else, the compounding of which constitutes that something. If ink (Dinte) is said to consist of ink again, the meaning of the question regarding the something else of which the ink consists is missed; the question is not answered but is simply repeated. The further question would then be whether that of which we speak is supposed to consist of something or not. But, as such, a composite is just that, an aggregate made up of something else. - (loc. cit.)

This appears to be a defense of the claim that a composite object must consist of something of a different kind. Hegel indeed makes an interesting observation here: If we wonder what ink consists of, and we are told that it consists of ink, we will not feel enlightened. But what exactly does this show? Does it show, in particular, the falsity of 'ink consists of ink'?

Generally speaking, there is a range of criteria that determine whether in a given context a particular reply to a question raised will count as a good answer. In normal contexts we want a satisfactory answer to be true (though there are contexts in which the falsity of an answer does not count against it, e.g. in the context of certain games). But truth alone does not suffice. An answer should also be informative and not merely provide information the questioner already possesses. Imagine you ask someone 'Who is the current president?' and the person answers 'The current president is the current president.' It is clear that you would find the answer unsatisfactory. But it is equally clear that this is not because the answer is false. It is because it carries no informational value with respect to your interests of inquiry; in fact, because of its tautological character it hardly carries any informational value (though it is not quite a logical truth, since it presupposes that there is a current president).

Moreover, a questioner often pursues particular goals of inquiry that are met only by answers of a particular sort. Thus, in ordinary contexts in which you were to ask what ink consists of, you would have a certain kind of composition in mind you 
want to hear about. Presumably, the most natural alternatives are that you either want to know how to produce ink from other materials, or that you want to know about the molecular structure of ink. Your interest will determine a range of answers that could be satisfactory and a range of answers that could not. If you are interested in how to mix ink from other substances, then you will not want to hear that ink consists of ink, whether this is true or not; nor will you want to hear that ink consists of these or those molecules, since this will not bring you closer to your goal either (unless you really excel in chemistry). If, however, you are interested in the molecular structure of ink, then being told that you can create ink by mixing soot, glue, and water will not satisfy your needs (again: unless you excel in chemistry).

So whether an answer to a posed question is satisfactory is not determined solely by the truth or falsity of the answer; a true statement may well fare badly as an answer to a question because it does not meet the intentions of the questioner. This latter factor already explains why, in any ordinary context, 'ink consists of ink' will count as a bad answer to the question 'What does ink consist of?'

But Hegel moreover seems to think that 'ink consists of ink' is false (and conceptually so, since he considers its negation tautological). And here one may disagree. At least it is plainly true that, generically speaking, portions of ink consist of further portions of ink (with the exception of minimal portions of ink; but since these are special cases, the claim that portions of ink consist of portions of ink is still true as a generic statement rather than a strictly universal one). Presumably, this lends a reading to 'ink consists of ink' on which it is true. Notice also that in this reading of 'ink consists of ink', the statement is far from trivial. Clearly, the statement form ' $\varphi$ consists of $\varphi$ ' has many false instances. A sandwich, for instance, does not consist of further sandwiches. (At least in general; in some strange corner of the world, Yorkshire perhaps, there may be exceptions to the rule, since a sandwich made of sandwiches is not an impossible object.) That a portion of ink consists of further portions of ink accordingly carries some genuine informational value, since it distinguishes ink from certain other things.

So while Hegel correctly observes that 'ink consists of ink' will not satisfy a typical questioner who asks what ink consists of, this observation does not warrant the conclusion that 'ink consists of ink' is false; and insofar that sentence can mean that portions of ink consist of further portions of ink, it is actually true.

But Hegel is not quite finished yet. He continues:

If the simple which is said to be the other of the composite is taken to be only a relatively simple which, for itself, is composite in turn, then the question stands as before. Figurative representation has in view, say, only this or that composite, to which this or that something might also be assigned as its simple element, although for itself the latter is a composite. But at issue here is the composite as such. (loc. cit.)

Here Hegel contrasts this or that individual composite object with the composite as such. And he acknowledges that when we want to know what a given composite object consists of, we may be content when we know that it consists of certain other things that are themselves composite. But if we want to know what the composite as 
such consists of, he insists, the answer must not make recourse to composite things again.

What does he mean by the composite as such, though? The contrast with a particular composite thing he draws is instructive and suggests that he means the plurality of all composite things. His point seems to be that when we do not talk about the composition of an individual object but instead want to say something perfectly general about what composite things consist of, we cannot say that the composite things (or: all composite things) consist of composite things. But why not? In a gunky world, that is exactly the right thing to say. And we're still within an argument that is meant to rule out the gunky world; so we cannot presuppose its being ruled out already.

Taking stock, Hegel's argument for Атоміsм is based on the claim that a composite object must consist of something else, which he regards as a tautology. But while it seems conceptually true that a whole must have parts that are non-identical to it, one may indeed doubt that a whole must consist of parts that are of a different kind than the whole. It is this latter claim, however, that Hegel needs for his argument, and he has given no strong reason to accept it.

\subsection{Back to Bolzano's Argument}

Enough about Hegel. As we saw, Bolzano comments on his own argument for Aтоміsм that Hegel 'viewed the matter in the same way.' Now while one can certainly make out some interesting similarities between the passages from Bolzano and Hegel, and while Bolzano may indeed have been inspired by Hegel, there are crucial differences between the two pieces of reasoning. Most importantly, unlike Hegel, Bolzano does not consider it to be a tautology that wholes consist of something of a different kind; and unlike Bolzano, Hegel does not phrase his argument in terms of grounding and explanation. Because of these differences, Bolzano's argument is in much better standing. It has a convincing starting assumption, namely that compositeness is not a fundamental property but rather a grounded one. So, Bolzano may actually give Hegel more credit than is due; but such an intellectual modesty would not be untypical for him.

Now let us see whether the existing similarities between the arguments can help us get a better grip on Bolzano's argument. Recall the two elements that were most obscure in Bolzano's text:

(i) He contrasts a compositeness of a certain kind with the compositeness in general that 'takes place' at an object.

(ii) He says that a sufficient explanation invokes conditions that require no further condition, but he cannot really mean this; for, the sufficient explanation should invoke the simple parts of a complex object, which are often conditioned themselves.

For each of these puzzles, we can gather a helpful clue from Hegel's text.

First, Bolzano's contrast between the compositeness of a specific sort and the compositeness in general seems to mirror the contrast Hegel drew between the 
compositeness of a particular and compositeness as such. We have seen that Hegel's contrast was that between an individual (a particular composite object) and a plurality, in fact: a totality (the composite as such). I suggest that Bolzano makes the same sort of contrast between a single entity and many entities. Incidentally, this interpretation is not only suggested by Hegel's passage to which Bolzano refers but it is also in harmony with what Bolzano elsewhere says about the phrases 'in general' and 'as such' ('überhaupt' and 'an sich'): He thinks these phrases are normally used to indicate that we take a particular phrase or idea in its full generality, rather than implicitly placing some restriction on its extension. ${ }^{24}$ On his view, then, combining 'in general' with a term presupposes that the extension of the term qualified comprises a plurality of entities.

Now unlike Hegel, Bolzano does not contrast an individual composite object and many such objects, but rather an individual property-compositeness of a specific kind-and a plurality of properties: compositeness in general. The crucial question is: What plurality of properties may Bolzano have in mind? In what sense are there different properties each of which is a kind of compositeness?

Here it helps to recall that Bolzano himself stresses that a composite thing can be decomposed in different ways, and in different degrees of granularity: in the case of a line several decompositions are possible, for instance bisections, trisections, etc. In correspondence to the variety of possible decompositions, a line has several properties that can be called its composition properties. For instance: being composed of two halves; but also: being composed of three-thirds; being composed of those four quarters, etc. More generally, for any entities, the property of being composed of those entities is a composition property. The compositeness in general that we find at an object (or, to use Bolzano's quaint expression: that takes place at the object) can then be seen as comprising all the composition properties of the object. ${ }^{25}$

Second, recall Hegel's observation that when we ask what ink consists of, we do not want to hear that ink consists of ink. This can serve as a clue for Bolzano's talk about sufficient explanations which must explain by invoking a condition that requires no further condition. What he may rather mean is that it requires no further condition of the same sort that was required before (do not 'explain' ink with ink). A sufficient explanation of, say, life in general, must not invoke

\footnotetext{
24 WL I, §57.1, p. 247.

25 On an alternative interpretation, Bolzano's contrast between the compositeness of a certain kind and the compositeness in general is that between a more specific property (a determinate) and a less specific one (a determinable). But the interpretation of the contrast as that between a single composition property and a plurality thereof is a better match for the available textual clues, since (i) it takes into account that Bolzano himself draws attention to multiple decompositions, (ii) it makes sense of Bolzano's reference to Hegel, and (iii) it is in line with Bolzano's own explication of the phrase 'in general' as an indicator that one should consider the full extension of a term. Moreover, the single/plurality interpretation yields the more interesting argument; on the determinate/determinable interpretation there is a straightforward objection: Bolzano admits that composite parts of an object provide a ground for a specific kind of compositeness - on the current reading: a determinate-but denies they provide one for compositeness in general-on the current reading: a determinable. But facts about determinates ground facts about determinables (a scarlet thing is red because it is scarlet). So by providing a ground for the determinate you provide one for the determinable.
} 
living beings in the explanation. And a sufficient explanation of compositeness in general must not invoke composite beings in the explanation. This reading lends a sense to Bolzano's talk about sufficient explanation that makes it coherent with his further views. It allows that a sufficient explanation of the compositeness of an object proceeds in terms of its atomic parts, even if those parts are themselves conditioned entities.

Moreover, on this reading, it is indeed true that a sufficient explanation of an object's compositeness in general cannot proceed in terms of composite parts of the object. To see this, consider an example of a composite object, a line. How can its compositeness in general be explained? We know that its compositeness should be explainable in terms of parts that compose the line. Now consider the putative explanation that its two halves compose the line. It is clearly insufficient; for, while it explains one composition property of the line (being composed of two halves), it leaves others unexplained (e.g. being composed by four quarters). So it does not explain the compositeness in general exemplified by the line. An explanation in terms of a finer division will fare somewhat better. If, for instance, the explanation offered is that four quarters compose the line, this accounts for more than one of its composition properties: It immediately explains the line's being composed of four quarters; and it mediately explains its being composed of two halves, since each of the two halves is itself composed by two of the quarters. But no explanation that proceeds in terms of composite parts of the line can account for all its composition properties, because there will always be finer divisions still not covered by the explanation. Only an explanation in terms of simple parts can account for all the composition properties, and hence for the compositeness of the line in general.

So, if we are given a composite object, a sufficient explanation of its compositeness in general must be all-encompassing, that is, it must account for all the composition properties of the object; and because of that, it must not take recourse to composite parts of the thing in question. Putting this together, we arrive at the following argument:

The Foundational Argument for Atomism

$\mathbf{P}_{1} \quad$ For every composite object $x$ :

The compositeness of $x$ has an explanation in terms of $x$ 's parts.

$\mathbf{P}_{2}$ For every composite object $x$ :

A sufficient explanation of $x$ 's compositeness in general must not invoke any composite parts of $x$ in its explanans.

$\mathbf{C}_{1}$ For every composite object $x$ :

$x$ 's compositeness in general has an explanation in terms of atomic parts of $x$.

$\mathbf{C}_{2} \quad$ For every composite object $x$ :

$x$ has atomic parts. 
(The step from $\mathbf{C}_{\mathbf{1}}$ to $\mathbf{C}_{\mathbf{2}}$ is warranted since explanations, in the pertinent understanding of the term, adduce grounds and grounding is factive.)

That is, I think, a sober reconstruction of Bolzano's somewhat obscure passage quoted in Sect. 3.2 (to make it explicit, premise $\mathbf{P}_{\mathbf{1}}$ captures the import of [i], and premise $\mathbf{P}_{\mathbf{2}}$ captures the combined import of [ii] and [iii].). But it is more than that; it is also a beautiful argument with two plausible premises each of which I defended above: compositeness is not a fundamental property and thus must be explainable, while an all-encompassing explanation of the compositeness of an object must not take recourse to composite parts of the object. The core idea of the argument can be expressed in a slogan: There must be atoms in order to sufficiently account for the compositeness of composite things.

Let us briefly return to a comparison with Hegel's reasoning, which may highlight a strength of Bolzano's argument. Hegel claims that we may in certain situations say about a particular composite object that it consists of further composite objects; but if we want to make a perfectly general claim about composite objects, he thinks, we cannot say that they consist of composite objects. Against this, I objected that in a gunky world this is exactly what we should say, and Hegel does not give us an argument against the possibility of gunky worlds. Now consider Bolzano's argument. Once it is accepted that compositeness is not a fundamental property, his argument provides a case against gunky worlds: in such worlds, there would be no sufficient explanation of the compositeness of a composite object. So if it is accepted that compositeness is not fundamental, the argument provides a case against gunky worlds.

Let me note, finally, that insofar the premises of the argument have a claim to be conceptual truths, the argument may even support the necessary truth of Атоміsм.

\subsection{From Atomism to Fundamentalism}

Interestingly, the FOUNDATIONAL ARGUMENT can be generalized to other issues apart from Aтоміsm. In particular, it can shed new light on the issue of FundaMENTALISM that I addressed earlier in this paper (see Sect. 2) when I discussed Bolzano's and Schaffer's quick arguments for Fundamentalism. I maintained that what they have to say about the issue is far too brief to be compelling. But it turns out that we can easily transform the Foundational Argument for Atomism into one for FundaMENTALisM. To do this, we start with the premise that the groundedness of a truth has an explanation in terms of its grounds. For, groundedness is not a fundamental property. Given a grounded truth $x$, it makes sense to ask what makes this truth a grounded one. And a good answer to this question refers to the grounds of $x$ : that these or those other truths ground $x$ makes $x$ a grounded truth. Now we modify the second premise of the argument accordingly by replacing talk about compositeness with talk about groundedness, and talk about parts with talk about grounds. We then get the following argument to the effect that grounded truths must be explainable in terms of ungrounded, i.e. fundamental truths: 


\section{The Foundational Argument for Fundamentalism}

$\mathbf{P}_{1} \quad$ For every grounded truth $x$ :

The groundedness of $x$ has an explanation in terms of $x$ 's grounds.

$\mathbf{P}_{2}$ For every grounded truth $x$ :

A sufficient explanation of $x$ 's groundedness in general must not invoke any grounded grounds of $x$ in its explanans.

$\mathbf{C}_{1}$ For every grounded truth $x$ :

$x$ 's groundedness in general has an explanation in terms of fundamental (i.e. ungrounded) grounds of $x$.

$\mathbf{C}_{2}$ For every grounded truth $x$ :

$x$ has fundamental (i.e. ungrounded) grounds.

So here we have a beautiful argument for FundAMEnTALisM. Its core idea can be stated in a slogan: There must be fundamental truths in order to sufficiently account for the groundedness of derivative truths. ${ }^{26}$

It even makes sense to wonder whether Bolzano and Schaffer may have been gesturing at this sort of argument, even if not clearly and distinctly, when they put forth their quick and condensed arguments for FunDAMENTALISM; but that is speculation, of course.

Note finally, though, that the parallel between the Foundational Argument for ATOMism and that for Fundamentalism puts pressure on someone who endorses one of them to endorse the other as well. This is relevant both to Bolzano and to Schaffer. For in their view, the two issues are not a par. As I remarked earlier, the mature Bolzano thinks he lacks a strong argument for FundamenTALISM; but he endorses the Foundational Argument for Atomism. Schaffer, on the contrary, puts forth an argument for Fundamentalism which may be gesturing at the Foundational Argument, but he endorses no such argument for AтоміSM. In fact, in one of his arguments for monism - the thesis that the only fundamental entity is the cosmos-he presupposes FundAmENTALism and the possible failure of Aтомism (see Schaffer 2010, §2.4). His argument, in an (oversimplified) nutshell is: Gunky worlds are possible; the only candidate for a fundamental entity in such a world is the cosmos; hence we should endorse monism. So to the extent that Schaffer would sympathize with the FounDational Argument for Fundamentalism, it may partially undermine his case for monism.

\subsection{A Logical Gap in the Foundational Argument}

Let me return to the Foundational Argument for Fundamentalism. Unfortunately, I have to pour some cold water onto it now. While I think it is a beautiful argument,

${ }^{26}$ Bliss (2019) also proposes an argument along these lines. 
and while I have argued that its two premises are indeed quite plausible, there is nevertheless a grave problem. Let me explain.

The argument may appear valid at first glance. But it would only be valid if its first premise ensured that there is a sufficient explanation of an object's compositeness in general. Then the second premise could kick in and lead us to the conclusion. However, the first premise does not provide the required input for the second premise. To see this, consider first how we have to understand the first premise in light of the discussion. We know that what matters to Bolzano's argument are several composition properties, and not just the single property of being composed (from some parts or others). So, as the first premise of the argument stands, it contains a misleading definite article. Since we are talking about several properties, the premise should be understood as a universal quantification in disguise: every composition property of an object is explainable in terms of the object's parts. So for the sake of explicitness, let us state the premise as a universal quantification:

$\mathbf{P}_{1 *} \quad$ For every composite object $x$ :

Every composition property of $x$ has an explanation in terms of $x$ 's parts.

Unpacking the claim like this does not make the premise any less plausible. But it helps realize that the logic of the argument is flawed. For, in order to activate the second premise, it has to be ensured that there is a sufficient explanation of the compositeness in general that we find at an object. Now if the compositeness in general were itself one of the composition properties of the object, the argument would go through: the first premise would require that every composition property of $x$ has an explanation in terms of $x$ 's parts; the second premise would ensure that a particular composition property cannot be explained in terms of composite parts; so this composition property would have to be explained in terms of atomic parts.

But the compositeness in general we find at an object is not one of its composition properties. Instead, the phrase 'compositeness in general' is used to talk about all the composition properties at once: An explanation of $x$ 's compositeness in general is meant to account for every composition property of $x$. Must there be such an explanation if we accept premise $\mathbf{P}_{1^{*}}$ ? No. Premise $\mathbf{P}_{1^{*}}$ says that every composition property has an explanation. But the second premise demands something stronger, namely that there be an explanation (i.e. a single one) of all the composition properties of a thing.

A formalization of the affair helps to drive the point home. From the claim made in the first premise:

$\forall x(x$ is a composition property $\rightarrow \exists y(y$ is an explanation of $x)$ )

we are not entitled to infer:

$\exists y \forall x(x$ is a composition property $\rightarrow(y$ is an explanation of $x))$

But this is exactly what would be required for the second premise to take over. 
What we have here is an instance of a classical fallacy: For-all-one does not entail one-for-all. That every mammal was born from a mother does not entail that there is one mother who gave birth to every mammal. And that for every composition property there's an explanation does not entail that there is one explanation that explains all the composition properties. ${ }^{27}$

So, the premises of the Foundational Argument do not warrant its conclusion. We would need an extra premise which requires a one-for-all explanation. But while the first premise of the argument is in itself plausible and a good starting pointcomposition properties are not fundamental, since they are relational by nature and grounded in relations-, the one-for-all requirement is not. In general, we do not expect that for every given sort of phenomenon there must be a single explanation which explains all its instances at once. Why should we? So, the Foundational ARgument is in need of a supporting argument showing that in the case of compositeness, we may presuppose that there is a one-for-all explanation. Neither Hegel's nor Bolzano's considerations contain any argument of that sort.

I conclude that there is work to do for the proponent of the Foundational Argument(s). And I may add that personally I suspect this might be lost cause. I find it hard to see how an argument should look like that licenses the assumption that there is a one-for-all explanation for phenomena such as compositeness or groundedness. But I am open to suggestions here.

\section{Conclusion}

Let me wrap up. I have discussed two claims about the structure of reality; both assert that there are minimal elements in the structure induced by a certain relation; grounding on the one hand, and parthood on the other. In a passage that is untypically obscure, Bolzano proposes an argument for Aтоміsм. With the aid of Hegel, I tried to extract a clear and precise argument from that passage, arriving at the Foundational Argument. This argument deserves our attention, since it prima facie makes a strong case for АтоміSм, and can moreover be transformed into an argument for FundAMENTALISM. The argument is based on what I regard as a correct contention: If there is an all-encompassing account of the groundedness of derivative truths, or of the compositeness of composite objects, then there must be minimal elements in the pertinent structures. But as I furthermore argued, the argument leaves a crucial question unanswered: What would warrant the assumption that there are such explanations in the first place?

I gathered all this on a trip to the history of philosophy, more precisely, the history of metaphysics. I hope I have thereby shown that such a trip can be intellectually

\footnotetext{
27 Question: Isn't it uncharitable to attribute this fallacy to Bolzano, a well-trained logician? Answer: No. The fallacy is well hidden from sight as long as the logical form of the argument has not been carved out. As long as one reasons informally, it is all too easy to rely on implicit inferences that are fallacious, even for trained logicians. Thus the sort of fallacy may also play a role for Schaffer's inheritance argument (see Sect. 2), which might be spelled out as follows: Every inheritance presupposes some prior possession; therefore, there must be some possession that is prior to every inheritance. A non-sequitur.
} 
rewarding not only for historians of philosophy, but as a genuine contribution to contemporary debates.

Acknowledgements Open Access funding provided by Projekt DEAL. This paper is based on the Erkenntnis lecture that I delivered in September 2018 at the conference GAP.10 in Cologne. Being invited to give this lecture was a really unique honor for me, and I am still as grateful for it as I feel humbled by it. I presented earlier versions of the paper at workshops in Tutzing and Salzburg, and I would like to thank the audiences of my talks for the discussion; I am also grateful for very valuable comments by two referees of this journal. Finally, I would like to thank the Fritz Thyssen Stiftung for their financial support of my research project "Der Leibniz Böhmens" - die Leibniz'schen Elemente in Bernard Bolzanos philosophischem System.

Open Access This article is licensed under a Creative Commons Attribution 4.0 International License, which permits use, sharing, adaptation, distribution and reproduction in any medium or format, as long as you give appropriate credit to the original author(s) and the source, provide a link to the Creative Commons licence, and indicate if changes were made. The images or other third party material in this article are included in the article's Creative Commons licence, unless indicated otherwise in a credit line to the material. If material is not included in the article's Creative Commons licence and your intended use is not permitted by statutory regulation or exceeds the permitted use, you will need to obtain permission directly from the copyright holder. To view a copy of this licence, visit http://creativecommons.org/licen ses/by/4.0/.

\section{References}

Bliss, R. (2019). What work the fundamental? Erkenntnis, 84, 359-379.

Bolzano, B. [AT]. (1838). Athanasia, 2nd Edn. Sulzbach: Seidel.

Bolzano, B. [Beyträge]. (1810). Beyträge zu einer begründeteren Darstellung der Mathematik (Prag: Widtmann). English in: S. Russ (transl. \& ed.), The Mathematical Works of Bolzano (pp. 80-137). Oxford: OUP.

Bolzano, B. [RW]. (1834). Lehrbuch der Religionswissenschaft (4 vols.). Sulzbach: Seidel.

Bolzano, B. [WL]. (1837). Wissenschaftslehre (4 vols.). Sulzbach: Seidel. (In an English translation by R. George \& P. Rusnock: Theory of Science, Oxford: OUP).

Casari, E. (2016). Bolzano's logical system. Oxford: OUP.

Curd, P. (2019). Presocratic philosophy. In Edward N. Zalta (Ed.) The Stanford encyclopedia of philosophy (Summer 2019 Edition). https://plato.stanford.edu/archives/sum2019/entries/presocratics/.

Dixon, T. S. (2016). What is the well-foundedness of grounding? Mind, 125, 439-468.

Fine, K. (2012). Guide to ground. In F. Correia \& B. Schnieder (Eds.), Metaphysical grounding (pp. 37-80). Cambridge: CUP.

Hegel, G. W. F. [Science]. (2010). The science of logic. Translated and edited by George di Giovanni. Cambridge: CUP.

Künne, W. (1997). Propositions in Bolzano and Frege. Grazer Philosophische Studien, 53, $203-240$. Reprinted in: W. Künne (2008): Essays on Bolzano (pp. 157-96). St. Augustin: Academia.

Künne, W. (2001). Constituents of concepts: Bolzano vs. Frege. In A. Newen et al. (Eds.), Building on Frege, (pp. 267-87). Stanford: CSLI. Reprinted in W. Künne (2008). Essays on Bolzano (pp. 21132). St. Augustin: Academia.

Leibniz, G. W. [Monadology]. (1714). The monadology. In: L. E. Loemker (transl. \& ed.), G.W. Leibniz. Philosophical Papers and Letters (2nd ed., 2nd print) (pp. 643-53). Dordrecht: Kluwer.

Leibniz, G. W. [Principles]. (1714). The principles of nature and grace, based on reason. In: L. E. Loemker (transl. \& ed.), G.W. Leibniz. Philosophical Papers and Letters (2nd ed., 2nd print) (pp. 63642). Dordrecht: Kluwer.

Morscher, E. (2016). Bernard Bolzanos Lehre von Grund und Folge - eine axiomatische Rekonstruktion. St. Augustin: Academia.

Rosen, G. (2010). Metaphysical dependence: Grounding and reduction. In B. Hale \& A. Hoffmann (Eds.), Modality (pp. 109-135). Oxford: OUP. 
Roski, S. (2017). Bolzano's conception of grounding. Frankfurt: Klostermann.

Roski, S., \& Rumberg, A. (2016). Simplicity and economy in Bolzano's theory of grounding. Journal of the History of Philosophy, 54, 469-496.

Roski, S., \& Schnieder, B. (2019). Fundamental truths and the principle of sufficient reason in Bolzano's theory of grounding. Journal of the History of Philosophy, 57, 675-706.

Rumberg, A. (2013). Bolzano's concept of grounding (Abfolge) against the background of normal proofs. Review of Symbolic Logic, 6, 424-459.

Ryhdéhn, H. (2018). Grounding and ontological dependence. Synthese. https://doi.org/10.1007/s1122 9-018-1818-4.

Schaffer, J. (2009). On what grounds what. In D. Chalmers, et al. (Eds.), Metametaphysics (pp. 347-383). Oxford: OUP.

Schaffer, J. (2010). Monism: The priority of the whole. Philosophical Review, 119, 31-76.

Schnieder, B. (2014). Bolzano on Causation and Grounding. Journal of the History of Philosophy, 52, 309-337.

Schnieder, B. (2015). Das Meisterargument in Platons Euthyphron. History of Philosophy and Logical Analysis, 18, 227-257.

Schnieder, B. (2017). Grounding and dependence. Synthese. https://doi.org/10.1007/s11229-017-1378-z.

Simons, P. (2015). Bolzano's monadology. British Journal for the History of Philosophy, 23, 1074-1084.

Tatzel, A. (2002). Bolzano's theory of ground and consequence. Notre Dame Journal of Formal Logic, $43,1-25$.

Wilson, A. (2018). Metaphysical causation. Noûs, 52, 723-751.

Wolff, Chr. [Gedancken]. (1733). Vernünfftige Gedancken von Gott, der Welt, und der Seele des Menschen, auch allen Dingen überhaupt: den Liebhabern der Wahrheit mitgetheilet (5th Edn). Frankfurt a.M. \& Leipzig.

Publisher's Note Springer Nature remains neutral with regard to jurisdictional claims in published maps and institutional affiliations. 